\title{
PENYULUHAN TENTANG PENTINGNYA IMUNISASI PADA BAYI DI POSYANDU KASIH IBU DI DESA PELAWAN KECAMATAN PELAWAN KABUPATEN SAROLANGUN
}

\author{
Safitri \\ Program Studi D III Kebidanan STIKes Baiturrahim Jambi \\ Email: safitrypipit@gmail.com
}

\begin{abstract}
Immunization protects children against some diseases that can be prevented by immunization (PD3I). Every year more than 1.4 million children in the world die from various diseases that can actually be prevented by immunization. Although in reality there are now many mothers who bring their babies to medical personnel to get immunization, only a small of them are given counseling. In Pelawan Village $44.37 \%$ of toddler did not get complete basic immunization, the reason they lacked knowledge of $42.86 \%$ and busy $57.1 \%$. Target outcomes expected are: there is an increased knowledge an increase in knowledge between before and after counseling, and awareness of mothers to bring their children to Posyandu to get immunization. The method used is counseling. The results of dedication are an increase in knowledge and awareness of mothers to bring their children to get immunizations in an effort to prevent disease.
\end{abstract}

Keywords: Counseling; immunization; infant

\begin{abstract}
ABSTRAK
Imunisasi melindungi anak terhadap beberapa penyakit yang Dapat Dicegah Dengan Imunisasi (PD3I). Setiap tahun lebih dari 1,4 juta anak di dunia meninggal karena berbagai penyakit yang sebenarnya dapat dicegah dengan imunisasi. Meskipun pada kenyataannya sekarang telah banyak ibu yang membawa bayinya ke tenaga kesehatan untuk mendapatkan imuniasi, namun hanya sebagian kecil dari mereka yang diberikan konseling. Di Desa Pelawan $44,37 \%$ balita tidak mendapatkan imunisasi dasar lengkap dengan alasan kurang pengetahuan $42,86 \%$ dan repot $57,1 \%$. Target luaran yang diharapkan peningkatan pengetahuan antara sebelum dan setelah penyuluhan, serta kesadaran ibu untuk membawa anaknya ke Posyandu untuk mendapatkan imunisasi. Metode yang digunakan adalah penyuluhan. Hasil pengabdian terdapat peningkatan pengetahuan dan kesadaran ibu untuk membawa anaknya mendapatkan imunisasi dalam upaya pencegahan penyakit.
\end{abstract}

Kata Kunci: Penyuluhan; imunisasi; bayi

\section{PENDAHULUAN}

Imunisasi adalah suatu upaya untuk menimbulkan/meningkatkan kekebalan seseorang secara aktif terhadap suatu penyakit, sehingga bila suatu saat terpapar dengan penyakit tersebut tidak akan sakit atau hanya mengalami sakit ringan. Setiap tahun lebih dari 1,4 juta anak di dunia meninggal karena berbagai penyakit sebenarnya dapat dicegah dengan imunisasi. Beberapa penyakit menular yang termasuk ke dalam Penyakit yang dapat dicegah dengan Imunisasi (PD3I) antara lain TBC, Difteri, Tetanus, Hepatitis B, Pertusis, Campak, Polio, radang selaput otak, dan radang paru-paru. Anak yang telah diberi imunisasi akan terlindungi dari berbagai penyakit berbahaya tersebut, yang dapat menimbulkan kecacatan atau kematian (Kemenkes RI, 2016).

Berdasarkan hasil Survei Penduduk Antar Sensus (SUPAS) tahun 2015 menunjukkan AKB sebesar 22,23 per 1.000 kelahiran hidup, yang artinya sudah mencapai target MDG 2015 sebesar 23 per 1.000 
kelahiran hidup. Begitu pula dengan Angka Kematian Balita (AKABA) hasil SUPAS 2015 sebesar 26,29 per 1.000 kelahiran hidup, juga sudah memenuhi target MDG 2015 sebesar 32 per 1.000 kelahiran hidup. Hasil survei Riskesdas tahun 2013 didapatkan data cakupan imunisasi HB-0 (79,1\%), BCG (87,6\%), DPTHB-3 (75,6\%), Polio-4 (77,0\%), dan imunisasi campak $(82,1 \%)$. Survei ini dilakukan pada usia anak $12-23$ bulan. Adapun cakupan pemberian imunisasi sebesar 59,2\% imunisasi lengkap, $32,1 \%$ imunisasi tidak lengkap, dan $8,7 \%$ tidak pernah diimunisasi.

Imunisasi melindungi anak terhadap beberapa Penyakit yang Dapat Dicegah Dengan Imunisasi (PD3I). Seorang anak diimunisasi dengan vaksin yang disuntikkan pada lokasi tertentu atau diteteskan melalui mulut. Sebagai salah satu kelompok yang menjadi sasaran program imunisasi, setiap bayi wajib mendapatkan imunisasi dasar lengkap yang terdiri dari 1 dosis BCG, 3 dosis DPT-HB dan atau DPT-HB-Hib, 4 dosis polio, dan 1 dosis campak. Dari imunisasi dasar lengkap yang diwajibkan tersebut, campak merupakan imunisasi yang mendapat perhatian lebih, hal ini sesuai komitmen Indonesia pada global untuk mempertahankan cakupan imunisasi campak sebesar $90 \%$ secara tinggi dan merata. Hal ini terkait dengan realita bahwa campak adalah salah satu penyebab utama kematian pada balita. Dengan demikian pencegahan campak memiliki peran signifikan dalam penurunan AKB. Indonesia memiliki cakupan imunisasi campak yang sedikit lebih rendah daripada tahun 2014 , yaitu sebesar $92,3 \%$ pada tahun 2015 (Kemenkes RI, 2016).

Imunisasi dasar pada bayi seharusnya diberikan pada anak sesuai dengan umurnya. Pada kondisi ini, diharapkan sistem kekebalan tubuh dapat bekerja secara optimal. Namun, pada kondisi tertentu beberapa bayi tidak mendapatkan imunisasi dasar secara lengkap. Seperti kita ketahui, bahwa di masyarakat masih ada pemahaman yang berbeda mengenai imunisasi, sehingga masih banyak bayi dan balita yang tidak mendapatkan pelayanan imunisasi. Alasan yang disampaikan orangtua mengenai hal tersebut, antara lain karena anaknya takut panas, sering sakit, keluarga tidak mengizinkan, tempat imunisasi jauh, tidak tahu tempat imunisasi, serta sibuk/repot. Karena itu, pelayanan imunisasi harus ditingkatkan di berbagai unit pelayanan (Kemenkes RI, 2015).
Selain memiliki manfaat, imunisasi juga menimbulkan efek samping dalam pelaksanaannya. Dalam dunia kesehatan, fenomena ini dikenal juga dengan istilah adverse event atau lebih dikenal dengan kejadian ikutan pasca imunisasi (KIPI). Berdasarkan Riskesdas 2013, didapatkan bahwa dari 91,3 persen anak di Indonesia yang pernah diimunisasi, terdapat 33,4 persen yang pernah mengalami KIPI. Keluhan yang sering terjadi adalah kemerahan dan bengkak, sedangkan keluhan demam tinggi dialami 6,8 persen anak.

Berdasarkan hasil observasi, meskipun pada kenyataannya sekarang telah banyak ibu yang membawa bayinya ke tenaga kesehatan untuk mendapatkan imuniasi, namun hanya sebagian kecil dari mereka yang diberikan konseling mengenai imunisasi. Akibat dari kurangnya pengetahuan tentang imunisasi banyak ibu yang kemudian panik dan menyalahkan tenaga kesehatan untuk efek samping dari imunisasi yang mungkin bisa terjadi. Di Kabupaten Sarolangun Desa Pelawan $44,37 \%$ balita tidak mendapatkan imunisasi dasar lengkap dengan alasan kurang pengetahuan $42,86 \%$ dan repot $57,1 \%$.

Pengetahuan ibu terhadap imunisasi merupakan faktor yang sangat penting, agar ibu dapat cepat tanggap dan tahu apa yang harus dilakukan ketika timbul efek samping pada anaknya untuk mendapatkan cakupan kelengkapan imunisasi (Sarfaraz, 2017). Kurangnya pengetahuan orang tua terutama ibu akan membawa sikap negatif dan rasa takut akan efek samping imunisasi yang nantinya akan berdampak pada pandangan ibu dan kemauan ibu untuk membawa anaknya ke fasilitas kesehatan guna mendapatkan imunisasi. Sehingga ada ibu yang berpandangan bahwa imunisasi akan menjadi hal yang merugikan bagi anaknya (Septiarini, 2015).

Pemberian informasi melalui penyuluhan atau pendidikan kesehatan tentang imunisasi merupakan upaya promotif untuk meningkatkan pengetahuan tentang imunisasi dan preventif untuk pencegahan penyakit, sehingga mampu menumbuhkan kesadaran orangtua membawa anaknya ke Posyandu untuk mendapatkan imunisasi dasar secara lengkap (Fitriani, 2013).

\section{TARGET DAN LUARAN}

Target dalam kegiatan pengabdiaan kepada masyarakat ini adalah memberikan penyuluhan 
kesehatan tentang pentingnya imunisasi pada bayi kepada ibu-ibu yang terutama ibu agar membawa anaknya ke Posyandu untuk mendapatkan imunisasi dasar secara lengkap dalam upaya pencegahan penyakit. Adapun luaran dalam kegiatan pengabdian kepada ini adalah publikasi pada jurnal ilmiah dan meningkatkan kesadaran ibu untuk membawa anaknya ke tenaga kesehatan mendapatkan imunisasi dalam upaya pencegahan penyakit.

\section{METODE PELAKSANAAN}

Pengabdian kepada masyarakat ini dilaksanakan pada bulan Februari 2018 di Posyandu Kasih Ibu Desa Pelawan Kecamatan Pelawan Kabupaten Sarolangun. Sasaran kegiatan ini adalah ibu-ibu yang memiliki balita di Posyandu Kasih Ibu.

Kegiatan pengabdian kepada masyarakat ini, mendapat rekomendasi dari Kepala Desa Pelawan, Puskesmas Pelawan, Bidan Desa dan Kader setempat untuk memberikan informasi tentang imunisasi dasar lengkap melalui penyuluhan kepada ibu-ibu yang memiliki balita di Posyandu Kasih Ibu dengan metode ceramah disertai diskusi dan tanya jawab menggunakan media leaflet berisi informasi tentang imunisasi dasar lengkap.

Tahapan kegiatan pengabdian kepada masyarakat meliputi:

1. Mengkaji dan menganalisis data

2. Mengidentifikasi masalah

3. Menyusun rencana kegiatan

4. Menyusun SAP, materi, instrumen preposttest serta mendesain leaflet

5. Mengurus izin lokasi kegiatan

6. Melakukan pretest

7. Melakukan penyuluhan tentang imunisasi menggunakan leaflet sesuai SAP yang telah disusun

8. Melakukan posttest

9. Melakukan monitoring dan evaluasi

\section{HASIL DAN PEMBAHASAN}

Pelaksanaan kegiatan pengabdian kepada masyarakat berjalan sesuai dengan rencana yang disusun. Kegiatan ini dilaksanakan kepada 20 ibu yang memiliki balita di Posyandu kasih Ibu. Dalam pelaksanaan kegiatan ini Tim dibantu oleh bidan desa dan kader yang sedang bertugas di Posyandu tersebut.

Sebelum dilakukan penyuluhan tentang imunisasi tim melakukan pretest. Hasilnya hanya $45 \%$ ibu mampu menjelaskan pengertian imunisasi, 30\% ibu mampu menyebutkan tujuan imunisasi, $25 \%$ ibu mampu menguraikan penyakit yang dapat dicegah dengan imunisasi, $60 \%$ ibu mampu menyebutkan tempat mendapatkan imunisasi, $40 \%$ ibu mampu menyebutkan jadwal imunisasi, $45 \%$ ibu mampu menerangkan keadaan yang tidak memperbolehkan anak diimunisasi, dan 50\% ibu mampu menerangkan keadaan yang muncul setelah imunisasi.

Penyuluhan dalam pengabdian kepada masyarakat ini dilakukan dengan metode ceramah untuk menjelaskan ide, pengertian secara lisan disertai dengan diskusi dan tanya jawab sehingga ibu memahami apa yang diberikan dan disampaikan. Selain itu, materi yang diberikan ditampilkan melalui media leaflet yang berisi informasi penting tentang imunisasi dasar lengkap disertai gambargambar menarik sehingga ibu dapat dengan mudah menangkap informasi yang diberikan. Selama proses penyuluhan berlangsung disertai pembagian leaflet ibu-ibu sangat antusias mendengarkan sambil memberikan respon baik dalam diskusi, $80 \%$ ibu bertanya terkait dengan materi yang disampaikan.

Setelah diberikan informasi tentang tentang imunisasi tim melakukan posttest. Hasilnya mengalami peningkatan $85 \%$ ibu mampu menjelaskan pengertian imunisasi, $80 \%$ ibu mampu menyebutkan tujuan imunisasi, $80 \%$ ibu mampu menguraikan penyakit yang dapat dicegah dengan imunisasi, 100\% ibu mampu menyebutkan tempat mendapatkan imunisasi, $90 \%$ ibu mampu menyebutkan jadwal imunisasi, $85 \%$ ibu mampu menerangkan keadaan yang tidak memperbolehkan anak diimunisasi, dan $80 \%$ ibu mampu menerangkan keadaan yang muncul setelah imunisasi. Serta $100 \%$ ibu memiliki kesadaran membawa anaknya untuk mendapatkan imunisasi. 


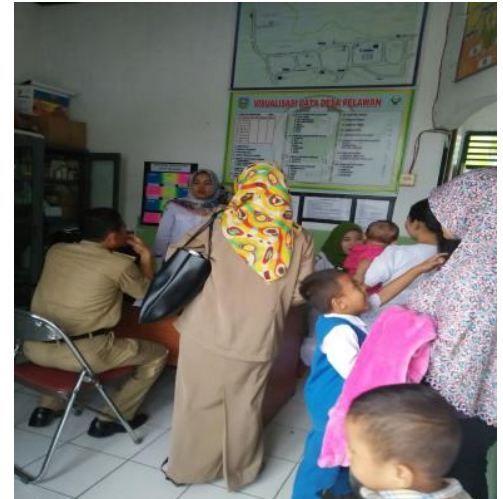

Gambar.1 Pengurusan izin pengabdian

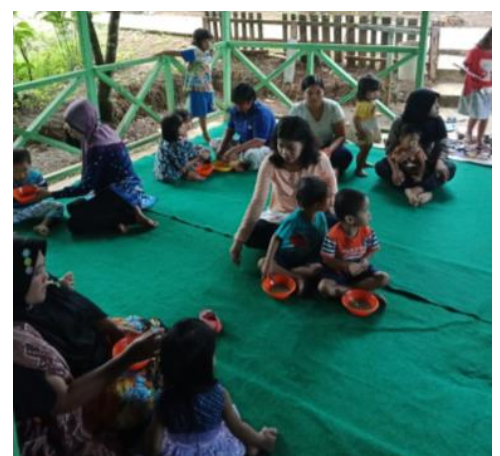

Gambar.2 Kegiatan Pengabdian

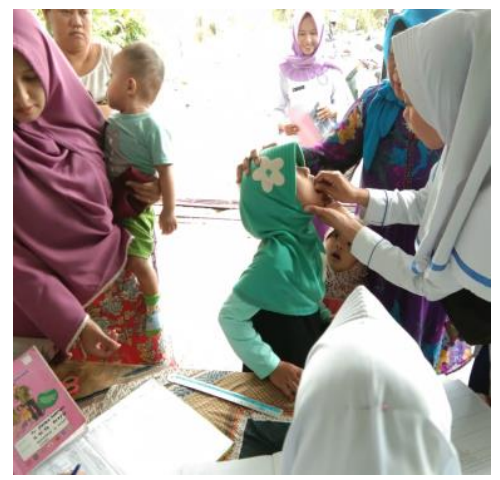

Gambar.3 Pemberian imunisasi

Hasil ini sejalan dengan penelitian yang dilakukan oleh Septiarini dkk, dinyatakan bahwa terdapat pengaruh bermakna penyuluhan terhadap pengetahuan ibu sebelum dan setelah diberikan penyuluhan $(\mathrm{p}<0,05)$. Salah satu faktor yang memengaruhi pengetahuan adalah karena kekurangan informasi. Pemberian informasi melalui pendidikan dan pelatihan akan meningkatkan pengetahuan, selanjutnya akan menimbulkan kesadaran dan akhirnya seseorang akan melakukan praktek sesuai dengan pengetahuan yang dimiliki, meskipun memerlukan waktu yang lama.

Hasil penelitian serupa oleh Bomboa dkk, dinyatakan ada pengaruh penyuluhan tentang imunisasi campak terhadap peningkatan pengetahuan ibu $(\mathrm{p}<0,05)$. Salah satu strategi untuk memperoleh perubahan perilaku adalah pemberian informasi untuk meningkatkan pengetahuan sehingga menimbulkan kesadaran dan dapat dilakukan dengan cara pemberian penyuluhan kesehatan.

Penelitian oleh Sukmaningtyas dkk, juga menujukkan terdapat pengaruh pemberian penyuluhan imunisasi terhadap peningkatan pengetahuan ibu tentang imunisasi dasar lengkap pada bayi $(p<0,05)$. Para ibu bayi mau datang menimbangkan bayinya secara rutin, bahkan merelakan bayinya mendapatkan imunisasi dasar lengkap tepat waktu, bukan karena pengetahuan yang mereka dapat tapi karena kebanyakan ibu mau melakukannya, sebagai ajang berkumpul para ibu terlebih ada rangsangan pemberian makanan tambahan untuk anak mereka, meskipun disisi lain ada kekuatiran saat bayinya diberi imunisasi DPT timbul panas pada tubuh bayi. Hal ini mungkin bisa jadi perhatian bagi tenaga kesehatan untuk melakukan penyuluhan secara rutin untuk menjawab kekhawatiran tersebut dan meningkatkan kesadaran ibu membawa anaknya ke Posyandu untuk mendapatkan imunisasi dasar secara lengkap.

\section{KESIMPULAN DAN SARAN}

\section{Kesimpulan}

Pelaksanaan kegiatan pengabdian kepada masyarakat yang dilakukan melalui penyuluhan tentang imunisasi kepada ibu-ibu balita di Posyandu Kasih Ibu mampu meningkatkan pengetahuan dan kesadaran ibu untuk membawa anaknya mendapatkan imunisasi dalam upaya pencegahan penyakit.

\section{Saran}

Disarankan kepada instansi yang terkait lebih mengoptimalkan peran tenaga kesehatan dalam memberikan penyuluhan secara rutin khususnya tentang imunisasi sehingga ibu-ibu balita lebih mengetahui dan mau membawa anaknya untuk mendapatkan imunisasi dasar secara lengkap. 
Jurnal Abdimas Kesehatan (JAK) Vol 1 No 2, Juni 2019

p-ISSN: 2655-9226

e-ISSN: 2655-9218

\section{UCAPAN TERIMAKASIH}

Tim pengabdian masyarakat mengucapkan terima kasih yang sebesarbesarnya kepada STIKes Baiturrahim Jambi atas bantuan dana dan fasilitas surat izin. Serta Kepala Desa Pelawan, Puskesmas Pelawan, Bidan Desa, Kader dan ibu-ibu setempat yang telah memfasilitasi dan memberikan izin tempat pengabdian kepada masyrakat ini, sehingga kegiatan pengabdian masyarakat ini dapat berjalan dengan lancar sesuai dengan waktu yang telah ditentukan.

\section{DAFTAR PUSTAKA}

Fitriani, S. 2013. Promosi Kesehatan. Graha Ilmu. Yogyakarta.

Kementerian Kesehatan RI. 2016. Profil Kesehatan Indonesia 2015. Kesehatan Kementerian Kesehatan RI. Jakarta.

Kementrian Kesehatan RI. 2015. Buku Ajar Imunisasi. Pusat Pendidikan dan Pelatihan Tenaga Kesehatan. Jakarta.
Kementrian Kesehatan RI. 2013. Riset Kesehatan Dasar 2013. Badan Penelitian dan Pengembangan Kesehatan Kementrian Kesehatan RI.

Sarfaraz MD, Athira A, Thotamsetty LMD, Ravilla SA, Nadikudi N, Doddayya D. Assessment of Knowledge, Attitude and Perception among Mothers towards Immunization in a Tertiary Care Teaching Hospital. Int J Community Med Publich Health. 2017;4(9):3429-35.

Septiarini RDP, Susanti AI, Nirmala SA. Pengaruh Penyuluhan Mengenai Imunisasi terhadap Pengetahuan dan Sikap Ibu di Desa Sukarapih Kecamatan Sukasari. JSK. 2015;1(2):43-54.

Sukmaningtyas W, Setiawan I. Pengaruh Penyuluhan Imunisasi terhadap Peningkatan Pengetahuan dan Kepatuhan Ibu tentang Imunisasi Dasar Lengkap pada Bayi Sebelum Usia 1 Tahun di Kecamatan Karangmoncol. Vina Medika. 2015;8(14):68-76. 